\title{
Os valores pessoais e o comprometimento social dos gestores: Um estudo sobre a Responsabilidade Social das Empresas no Brasil
}

Managers, Personal Values and Social Commitment: A study of social responsibility in companies in Brazil

Les valeurs personnelles et l'engagement social des gestionnaires: une étude sur la Responsabilité Sociale des Entreprises au Brésil

\section{Filipe Almeida}

\section{OpenEdition \\ Journals}

Edição electrónica

URL: http://journals.openedition.org/rccs/259

DOI: $10.4000 /$ rccs. 259

ISSN: 2182-7435

\section{Editora}

Centro de Estudos Sociais da Universidade de Coimbra

Edição impressa

Data de publição: 1 setembro 2009

Paginação: 145-166

ISSN: 0254-1106

Refêrencia eletrónica

Filipe Almeida, "Os valores pessoais e o comprometimento social dos gestores: Um estudo sobre a Responsabilidade Social das Empresas no Brasil », Revista Crítica de Ciências Sociais [Online], 86 | 2009, posto online no dia 01 dezembro 2012, consultado o 14 novembro 2019. URL : http:// journals.openedition.org/rccs/259

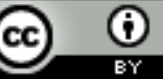




\section{Os valores pessoais e o comprometimento social dos gestores: Um estudo sobre a Responsabilidade Social das Empresas no Brasil}

O objectivo deste artigo é estudar a influência do sistema de valores pessoais dos gestores na sua atitude perante a Responsabilidade Social das Empresas (RSE), pressupondo-a como preditora da prática gerencial. As hipóteses de pesquisa foram testadas num estudo com 252 gestores brasileiros. Os resultados revelam que a predisposição para uma prática gerencial socialmente responsável é favorecida por um sistema de valores conservador, defensor da estabilidade e da ordem, da segurança e do cumprimento de normas colectivas, por oposição à influência negativa de valores pessoais centrados no bem-estar individual e na auto-promoção. Esta relação entre o sistema de valores e a atitude dos gestores perante a RSE só se verifica, no entanto, nos gestores com menos de 30 anos, o que sugere que a experiência profissional torna a adopção de práticas empresariais socialmente responsáveis independente do sistema de valores de quem decide, sobrepondo-se factores estratégicos e de contexto ao sistema de crenças pessoal.

Palavras-chave: valores humanos; comprometimento social; Responsabilidade Social das Empresas.

\section{Introdução}

Ao longo das últimas décadas, a preocupação com o bem-estar social e com o desenvolvimento sustentável passou a integrar o discurso empresarial, traduzindo-se também, com frequência, em práticas consideradas socialmente responsáveis. Esta alteração de políticas e de comportamentos gerenciais emergiu como uma resposta do sector empresarial às reivindicações de uma opinião pública mais global, mais esclarecida e mais vigilante, em busca de legitimação da sua actividade com fins lucrativos e do sistema capitalista que a suporta. A intensificação da discussão sobre os limites da responsabilidade empresarial parece também ter despertado a atenção da sociedade para inúmeros comportamentos empresariais moralmente condenáveis, tendo gerado uma pressão suplementar sobre os gestores e empresários para 
minimizarem os impactos sociais negativos e evidenciarem as contribuições positivas da sua actividade. A Responsabilidade Social das Empresas (RSE) surge, assim, como um movimento legitimador da acção empresarial que traz novas exigências para as empresas e promove a transformação de crenças e de modelos de gestão. Mas apesar do aparente consenso sobre as mudanças necessárias, os gestores e empresários divergem no entendimento sobre estas novas exigências e na forma como as incorporam nas estratégias que definem, nas políticas que impõem e nas práticas que valorizam. Os escândalos empresariais sucessivos dos últimos anos parecem confirmar a profunda divergência que ainda subsiste entre discursos, entre práticas e, em alguns casos, entre o discurso e a prática das mesmas entidades. $\mathrm{Na}$ origem destas divergências está, entre outros factores, a interpretação que cada responsável empresarial faz do conceito, das implicações e dos limites da RSE, nele incluindo os seus desdobramentos e extensões teóricas, tais como a cidadania empresarial, a governação corporativa, o desenvolvimento sustentável ou a orientação para os stakeholders. Mantendo uma ampla liberdade de decisão estratégica que nem sempre se regula pelo interesse exclusivo dos accionistas (Eisenhardt, 1989), mas reflecte a arbitrariedade dos interesses e das vontades pessoais (Maclagan, 1998), os dirigentes empresariais integram na prática gerencial o seu sistema de crenças, os seus desejos, a sua visão do mundo e das relações humanas, a sua concepção da economia e até a sua ideologia política. Efectivamente, a finalidade económica e lucrativa da actividade empresarial não será, em muitas circunstâncias, o vínculo único que compromete as suas decisões. Por isso se revela importante estudar o pensamento dos dirigentes empresariais, buscando uma compreensão mais alargada sobre os motivos psicológicos e axiológicos que podem justificar os níveis diferenciados de adesão das empresas ao discurso sobre RSE e, mais do que isso, às práticas dele decorrentes.

As pesquisas sobre RSE têm dado especial atenção à discussão do conceito e das motivações estratégicas que podem justificar a sua integração na prática empresarial, buscando definir quais as melhores práticas, como avaliá-las ou porque devem ser implementadas. Tratando-se de um tema recente, são ainda raros os estudos sobre a visão pessoal dos gestores e dirigentes em relação a estas problemáticas. Assim, propõe-se uma abordagem da RSE centrada no gestor enquanto agente central no processo que envolve a adopção, por parte das empresas, de políticas e de práticas alinhadas com as expectativas e necessidades da sociedade. O objectivo deste estudo é analisar, em particular, como o sistema de valores humanos dos gestores influencia a sua atitude geral perante a RSE, pressupondo que esta é preditora do seu comportamento enquanto decisor empresarial. 
Ao estudar o sistema de crenças do gestor, relacionando os seus valores pessoais com a sua atitude perante a RSE, espera-se contribuir para reforçar o entendimento das decisões gerenciais como fruto de factores não exclusivamente organizacionais ou de mercado, mas também de factores de ordem psicológica, estritamente individuais, que podem influenciar as políticas de empresa, o relacionamento com os stakeholders, a concepção de negócio e até mesmo as escolhas estratégicas de expansão. Para testar empiricamente estas relações, foram inquiridos por meio de um questionário estruturado 252 gestores brasileiros, maioritariamente de São Paulo e do Rio de Janeiro.

\section{A RSE e o comprometimento social dos gestores}

Tratando-se de um tema com implicações profundas nos modelos de organização económica, social e política das sociedades contemporâneas, que inevitavelmente conduz ao questionamento do sistema capitalista, dos seus fundamentos e dos seus efeitos, a RSE tem-se revelado um campo teórico especialmente fértil em polémica e controvérsia, gerando oposições ideológicas e inspirando múltiplos ângulos de análise dos papéis das empresas e do Estado na sociedade. Por isto, apesar de muito discutida durante as últimas décadas, uma das principais dificuldades que o estudo da RSE encerra resulta da diversidade de interpretações defendidas pelos autores que em todo o mundo pesquisam o assunto (Bakker et al., 2005). A inexistência de consenso reflecte, por um lado, a juventude e a complexidade do tema, comprometendo, no entanto, por outro, a validade da comparação entre argumentos, entre aplicações metodológicas e entre resultados alcançados em pesquisas realizadas por diferentes autores. O estudo da RSE exige, portanto, que cada autor esclareça o seu posicionamento sobre o conceito e a forma como interpreta o seu significado.

No Dicionário das Ciências Sociais, Birou (1976: 360) define responsabilidade como o "a obrigação moral que deriva do exercício de um cargo ou do cumprimento de uma missão". Quando se trata do caso específico da responsabilidade social, esta é entendida como "a responsabilidade daquele que é chamado a responder pelos seus actos face à sociedade ou à opinião pública, (...) na medida em que tais actos assumam dimensões ou consequências sociais" (Birou, 1976: 361). Estes actos podem referir-se tanto a deveres negativos (evitar o dano) como a deveres positivos (praticar o bem). Tal como esclarece Thiry-Cherques (2003: 33):

[...] a responsabilidade social compreende o dever de pessoas, grupos e instituições em relação à sociedade como um todo, ou seja, em relação a todas as pessoas, todos 
os grupos e todas as instituições. A responsabilidade é o que nos faz sujeitos e objectos da ética, do direito, das ideologias e, se quisermos, da fé. É o que nos torna passíveis de sanção, de castigo, de reprovação e de culpa.

Resulta daqui que a responsabilidade social das empresas constitui uma obrigação perante a sociedade, um dever ou conjunto de deveres que deriva da expectativa colectiva perante a prática organizacional. O voluntarismo empresarial tão frequentemente invocado para delimitar a RSE parece inconsistente com a própria noção de responsabilidade, confundindo a responsabilidade moral (mais centrada na análise dos motivos da acção) com a responsabilidade social (que inclui necessariamente outros vínculos além dos estritamente morais).

As principais concepções de RSE, embora convergentes nas ideias centrais, nem sempre respondem com clareza à questão nuclear sobre quais são, concretamente, as responsabilidades sociais de uma empresa, limitando-se a enunciar princípios gerais de conduta empresarial e de filosofia de gestão. Uma das tentativas mais bem sucedidas de teorizar as responsabilidades sociais das empresas é a proposta apresentada por Carroll em 1979, a qual resistiu, no essencial, até à actualidade, permanecendo amplamente aceite pela comunidade científica internacional (Acar et al., 2001). O autor estabelece quatro tipos específicos de responsabilidades sociais das empresas, identificadas com base nas expectativas da sociedade em relação ao desempenho empresarial: responsabilidades económicas, legais, éticas e filantrópicas. Carroll destaca a responsabilidade económica como base que sustenta todas as outras que são, por sua vez, assumidas pelas empresas de acordo com uma prioridade sequencial. Às responsabilidades económicas e legais que vinculam as empresas à sociedade, Carroll acrescenta as responsabilidades éticas - que se referem à exigência de uma conduta que, não sendo imposta por lei, seja alinhada com os códigos morais e com valores socialmente aceitáveis - e as responsabilidades filantrópicas - que implicam o envolvimento directo da empresa, por meio de contribuições financeiras ou transferência de recursos, em acções que visam melhorar o bem-estar da comunidade envolvente e promover o desenvolvimento social (Carroll, 1979, 1991, 1999; Ferrell et al., 2002). Desenvolvimentos posteriores apresentados por Wartick e Cochran (1985) e por Wood (1991) são elaborações teóricas que amplificam e esclarecem a proposta original de Carroll, mas não contrariam as suas premissas nem o seu desenho conceptual (Carroll, 1999).

Apesar das inovações relevantes da concepção de Carroll (1979) e da sua ampla divulgação no meio académico, o seu modelo ainda apresenta algumas fragilidades que comprometem a sua plena aplicabilidade. Entre elas, 
destaca-se a rigidez da formulação que estabelece um sentido ascendente unidireccional das responsabilidades, sugerindo uma hierarquia de prioridades que parece distorcer os próprios fundamentos equitativos da responsabilidade social. Por outro lado, o modelo parece sugerir também uma confusão entre o plano dos princípios e o plano das acções concretas, ao incluir uma responsabilidade filantrópica. A filantropia, tal como entendida actualmente, consiste numa transferência voluntária de recursos da sociedade civil em benefício de quem tem carências essenciais ou em nome de uma transformação social (Kisil, 2005). Ora esta contribuição da sociedade civil situa-se no plano dos comportamentos, entendidos como expressão da adesão a determinados princípios, crenças ou valores. A responsabilidade ética, animada pelo dever racional e, eventualmente, pelos sentimentos de amor pela humanidade e de generosidade que definem a essência da filantropia (Houaiss, 2002), pressupõe o compromisso moral que complementa os restantes - económico e legal -, sendo a filantropia uma das suas manifestações, entre outras possíveis. Portanto a filantropia, embora designando um sentimento, mas sendo entendida na actualidade como uma transferência de recursos, não deve ser considerada uma obrigação empresarial em si mesma. Deve, pois, constituir uma das possibilidades de exercício da responsabilidade ética das empresas.

Assim, a partir da proposta de Carroll, propõe-se uma reinterpretação da RSE, entendida como uma síntese dos compromissos que vinculam as empresas à sociedade que servem e da qual dependem, resumida nos princípios do seguinte modelo:

FIGURA 1 - Os Compromissos Sociais da Empresa

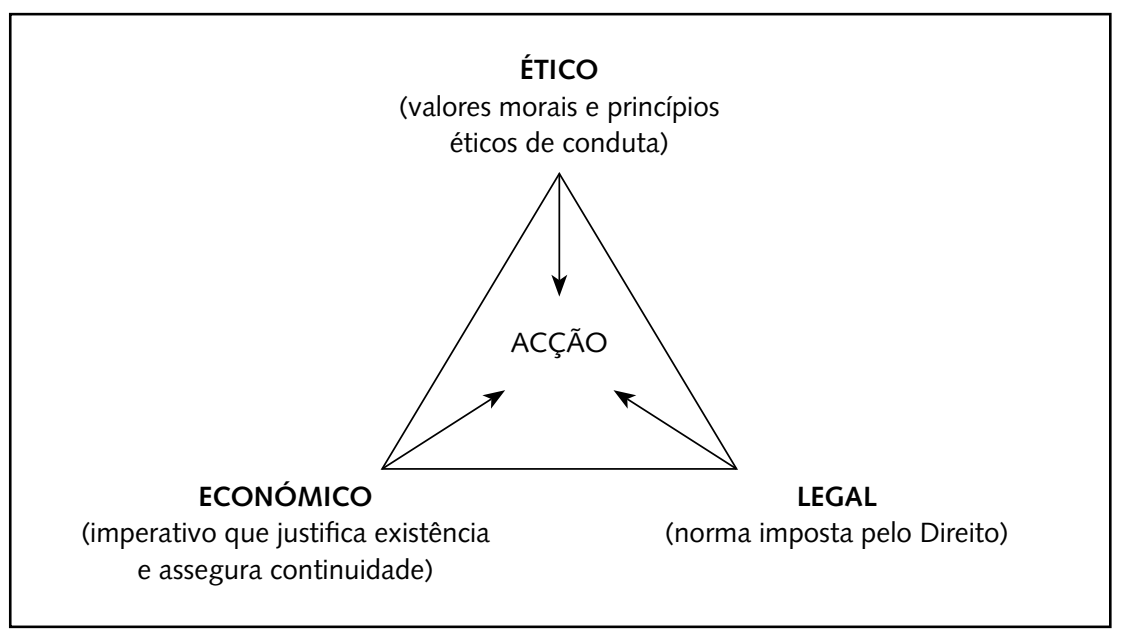


Segundo esta proposta, a RSE consiste no conjunto de obrigações sociais que decorrem do compromisso económico, legal e ético da empresa perante a sociedade. Os vértices do triângulo representam as três fontes de responsabilidade social que se estabelecem como princípios orientadores da acção da empresa. A RSE implicará um esforço permanente de articulação de políticas, estratégias e acções a fim de cumprir os deveres positivos (de acção) e negativos (de omissão) sugeridos pela finalidade económica, pelos princípios éticos e pela exigência de cumprimento da lei. A responsabilidade económica está relacionada com o objecto principal da actividade empresarial, o qual justifica a sua existência e assegura a sua sobrevivência e sustentabilidade. Esta responsabilidade corresponde à obrigação de fornecer a sociedade com produtos e serviços de boa qualidade, investindo na inovação e buscando o lucro que permita o crescimento da empresa e a satisfação das legítimas expectativas dos accionistas. A responsabilidade legal implica a obrigação social de cumprir a legislação. Tratando-se de uma norma obrigatória imposta pelo Direito, a lei resulta, nas sociedades democráticas, de um desejo de regulação ratificado pela sociedade. A existência desta lei, no entanto, não é garantia do seu cumprimento. Os mecanismos sancionatórios geralmente inibem a sua transgressão, porém a empresa mantém liberdade de escolha sobre a adesão à lei em inúmeras circunstâncias da sua actividade, o que torna o seu cumprimento uma verdadeira fonte de responsabilidade perante a sociedade. Por fim, a responsabilidade ética respeita ao dever de agir segundo princípios morais alinhados com os valores sociais. Esta responsabilidade implica a adopção de um comportamento eticamente aceitável que, não sendo imposto pela lei ou pela finalidade económica, decorre de uma disposição para integrar na definição de políticas e de estratégias elementos e pretensões que previnam o eventual dano provocado pela acção empresarial e considerem positivamente a contribuição para o bem-estar social e para o desenvolvimento humano. Tal como formulado, a acção empresarial será um produto da importância atribuída a cada uma das responsabilidades, ou seja, da influência exercida pela intersecção dos mandamentos por elas sugeridos sobre as políticas, estratégias e práticas empresariais.

\section{Os valores humanos}

No mundo das ideias, a palavra "valor" contém uma diversidade de significados que, embora justifique a sua frequente evocação na linguagem corrente, dificulta a compreensão e o consenso em torno do que representa o conceito. Tal como refere Birou no Dicionário das Ciências Sociais, "a palavra 'valor' é uma das que possuem significação mais rica, mais 
complexa e mais difícil de definir" (1976: 419). O autor descreve valor como a "capacidade que um objecto (coisa, ideia ou outra pessoa) tem de satisfazer um desejo, uma necessidade ou uma aspiração humana" (Birou, 1976: 419), esclarecendo ainda que a atribuição de valor a uma qualquer realidade implica o reconhecimento de que essa realidade propicia um bem, concluindo que "reflectir sobre os valores é reflectir sobre o que é um bem, quer a nível do destino da sociedade, quer a nível do destino pessoal" (Birou, 1976: 420). Esta concepção remete o conceito de valor para o domínio da reflexão filosófica que questiona os fundamentos estruturantes da vida em sociedade e do sentido profundo das relações humanas. No campo das ciências sociais, o estudo dos valores humanos é uma conquista recente, marcada pelos ensaios pioneiros de Kluckhohn (1951) e as pesquisas empíricas de Allport, Vernon e Lindzey (1960), tendo atraído a atenção de muitos académicos que contribuíram com os seus trabalhos para a integração definitiva na linguagem sociológica e psicológica deste conceito de origem filosófica.

Actualmente, a teoria sobre os valores humanos básicos da autoria de Shalom Schwartz é uma das mais referenciadas no estudo empírico de valores, sendo a sua metodologia amplamente aceite e adoptada por investigadores de todo o mundo. Schwartz (2005) propõe "uma teoria unificadora para o campo da motivação humana, uma maneira de organizar as diferentes necessidades, motivos e objectivos propostos em outras teorias" (2005: 21). Para o efeito, os valores individuais representam, portanto, objectivos gerais que visam satisfazer necessidades humanas básicas, sendo definidos por Schwartz (1992) como metas desejáveis, trans-situacionais e de importância variável, que servem como princípios orientadores na vida das pessoas. Com base numa ampla pesquisa empírica realizada entre 1988 e 2002 envolvendo respostas de 64271 pessoas de 210 amostras de 67 países localizados em todos os continentes habitados (Schwartz, 2005), o autor identificou dez tipos motivacionais de valores capazes de caracterizar todo o espectro axiológico, incluindo neles 57 valores específicos. Cada um dos valores motivacionais representa, assim, o objectivo que visa ser alcançado com a adesão aos valores específicos que o constituem. Os dez tipos motivacionais de valores propostos por Schwartz são os seguintes, definidos pelos objectivos que representam: Autodeterminação (independência de pensamento e de acção); Estimulação (novidade e desafio na vida); Hedonismo (prazer individual associado essencialmente aos sentidos); Realização (êxito pessoal baseado na demonstração de competência); Poder (status social, domínio e controlo sobre pessoas e recursos); Segurança (harmonia e estabilidade da sociedade, das relações e de si mesmo); Conformidade (conduta alinhada 
com normas sociais e códigos colectivos); Tradição (respeito e aceitação dos costumes e ideias culturalmente estabelecidos); Benevolência (preservação e fortalecimento do bem-estar dos que estão próximos); Universalismo (apreço pelo bem comum e protecção da Natureza).

Os valores motivacionais têm, segundo a teoria, uma relação dinâmica entre si. As acções que buscam alcançar um determinado valor podem ser compatíveis ou conflituantes com a busca de outro valor. Assim, os valores motivacionais podem ser organizados numa estrutura circular, na qual os valores que se situam mais próximos entre si têm motivações subjacentes semelhantes e os mais distanciados terão motivações subjacentes mais antagónicas. Estas relações de complementaridade e de oposição foram confirmadas ao longo dos últimos anos não só pelos estudos de Schwartz, mas também por inúmeras pesquisas empíricas realizadas em diversas regiões do mundo (Spini, 2003; Esparza e Fernández, 2002; Sousa e Bradley, 2002; Tamayo et al., 2001; Knafo e Schwartz, 2001; Kozan e Ergin, 1999). A relação dinâmica entre valores motivacionais constitui, de facto, o principal diferencial da proposta de Schwartz, no âmbito da qual os valores são concebidos no quadro de uma teoria mais geral da motivação que explica a relação entre eles (Rohan, 2000), que os fundamenta filosoficamente e que permite clarificar a ligação dos sistemas de valores com outras dimensões da vida humana.

$\mathrm{Na}$ estrutura original de Schwartz, os dez valores motivacionais podem ainda ser agrupados em dois eixos de ordem superior que opõem a Abertura à Mudança (autodeterminação e estimulação) à Conservação (segurança, conformidade e tradição) e a Autopromoção (poder e realização) à Autotranscendência (universalismo e benevolência), constituindo estes pólos Valores de Ordem Superior (VOS). ${ }^{1} \mathrm{O}$ autor refere, no entanto, que os valores motivacionais podem ser agrupados em VOS diferentes da combinação identificada nas amostras originais, desde que respeitando a sua adjacência, a fim de se ajustarem às particularidades de cada estudo (Schwartz, 2005). Nesta pesquisa, além de se fixar o Hedonismo numa das categorias de ordem superior, a análise detalhada dos significados dos valores motivacionais e da sua relação com os compromissos sociais das empresas sugere também uma alteração das designações atribuídas aos eixos de ordem superior. A Figura 2 apresenta a estrutura circular que agrupa os valores motivacionais em dois eixos bipolares com as novas designações propostas para este estudo.

\footnotetext{
${ }^{1} \mathrm{O}$ valor motivacional Hedonismo tem elementos partilhados pelas dimensões Abertura à Mudança e Autopromoção.
} 
FIGURA 2 - Os Valores Motivacionais e os Valores de Ordem Superior

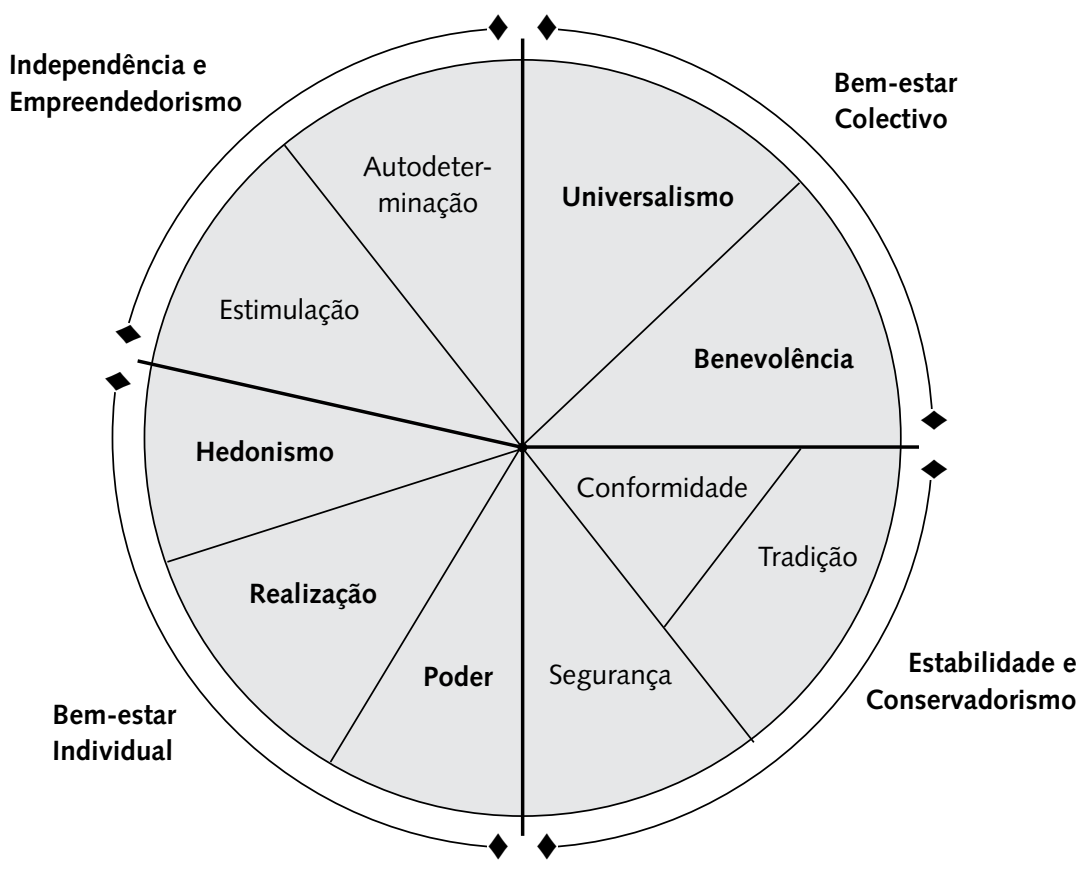

O primeiro eixo - que opõe o VOS Independência e Empreendedorismo ao VOS Estabilidade e Conservadorismo - ordena os valores em função da preferência pessoal pela independência de pensamento, de acção e abertura à mudança ou, pelo contrário, pela defesa da estabilidade, preservação da ordem e respeito pela tradição. O segundo eixo - que opõe o VOS Bem-estar Individual ao VOS Bem-estar Colectivo - refere-se à realização de valores centrados no bem-estar e no desenvolvimento individual ou orientados para o bem-estar e a harmonia colectiva.

A teoria dos valores motivacionais de Schwartz permite assim compreender, de forma estruturada, como se organiza e articula o sistema de valores de cada pessoa, com referência às metas que motivam a sua realização. Nos últimos anos multiplicaram-se as pesquisas sobre a relação dos sistemas de valores com atitudes e comportamentos manifestados em diversas áreas da gestão (Bhatta, 2004; Banerjee, 2004; Smith et al., 2002; Munene et al., 2000; Bigoness e Blakely, 1996). São, no entanto, ainda reduzidos os estudos que associem valores humanos à RSE, dificultados talvez pelas divergências conceptuais que ainda caracterizam o debate em torno de ambos os temas. A proposta central deste trabalho é precisamente o cruzamento desta duas dimensões, centrando a análise do sistema de valores nos eixos de ordem superior. 


\section{Um modelo teórico para a análise das atitudes dos gestores perante a RSE}

No plano gerencial, os gestores com responsabilidades estratégicas estão frequentemente expostos a dilemas que obrigam à tomada de decisões com base nas suas preferências éticas individuais (Watson, 2003). Hemingway e Maclagan (2004: 36) defendem, a este respeito, que "as decisões organizacionais dos gestores são motivadas por uma variedade de valores e de interesses pessoais, além dos objectivos corporativos oficiais". Assim, as decisões empresariais que envolvem escolhas directamente relacionadas com as responsabilidades sociais das empresas, ao contrário das decisões de gestão eticamente neutras, dependem fortemente do sistema de valores e dos critérios morais do responsável por essa decisão, podendo mesmo estes factores sobrepor-se aos critérios puramente económicos ou estratégicos. Assim, propõe-se nesta pesquisa estudar como o sistema de valores dos gestores influencia a sua atitude perante a RSE, a qual define o seu grau de comprometimento social no contexto das suas funções gerenciais. Esta atitude dos gestores perante a RSE é estudada enquanto determinante do comportamento, ou seja, como antecedente do Desempenho Social das Empresas, o qual não será objecto de estudo, embora represente uma projecção comportamental da atitude declarada pelo gestor que justifica a relevância prática do modelo em análise. ${ }^{2}$ Com base nos referenciais teóricos expostos, o modelo de análise e as hipóteses básicas subjacentes (HB) desagregam o sistema de valores pessoais nas suas dimensões de ordem superior, apresentando a seguinte formulação:

FIGURA 3 - Modelo de análise da influência dos valores pessoais na atitude perante a RSE

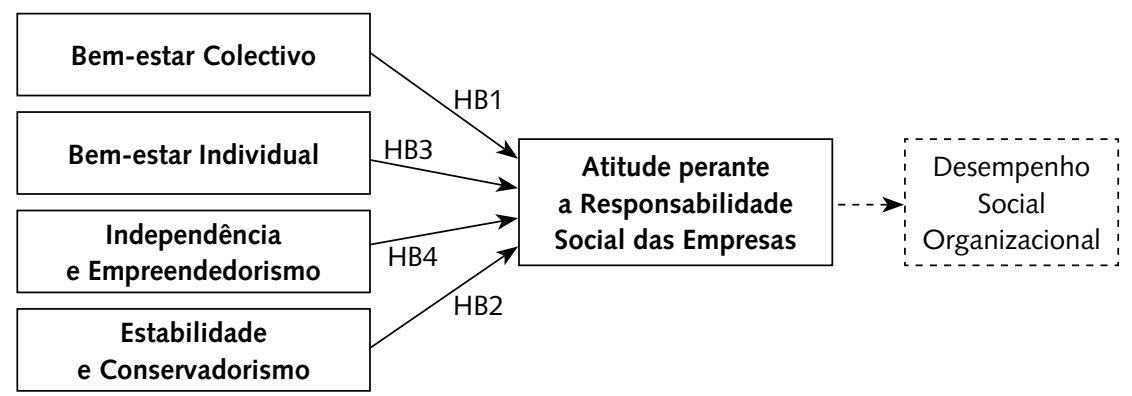

\footnotetext{
${ }^{2}$ Embora subsistam diferentes entendimentos sobre o conceito e as implicações das atitudes, estas são aqui definidas como uma categoria psicológica que, dirigindo-se a objectos particulares, representa uma predisposição para agir em conformidade com a atitude revelada. Uma atitude será, portanto, segundo esta perspectiva, um indicador da intenção de agir e do comportamento efectivo (Fishbein e Ajzen, 1975). Tratando-se do gestor, pressupõe-se que a sua atitude perante a RSE seja um indicador significativo da forma como ele projecta nas decisões empresariais esse posicionamento pessoal.
} 
O modelo de análise compreende um conjunto articulado de hipóteses subjacentes que se referem à influência do sistema de valores do responsável organizacional na sua atitude perante a RSE. Na estrutura circular de valores proposta por Schwartz (1992, 1994), os pólos de ordem superior da esquerda referem-se a valores centrados no próprio indivíduo e os pólos de ordem superior da direita referem-se a valores centrados nos outros, com referência aos seus interesses e às suas vontades. Nesta pesquisa, especula-se que os valores centrados nos outros promovem uma atitude gerencial favorável ao pleno exercício da RSE, enquanto os valores centrados no próprio agente constituem um bloqueio ao desenvolvimento de uma atitude gerencial socialmente responsável, tal como defendido nas hipóteses enunciadas.

HB 1: Os valores pessoais centrados no bem-estar colectivo influenciam positivamente uma atitude gerencial que favoreça o equilíbrio entre os compromissos sociais da empresa.

O exercício pleno da RSE impõe aos responsáveis organizacionais um esforço permanente de compromisso entre a satisfação de múltiplos interesses frequentemente divergentes. Ao compromisso económico - que assume prioridade natural no critério de decisão gerencial - acrescentam-se compromissos legais e éticos, os quais obrigam à consideração de interesses externos ao perímetro restrito do negócio propriamente dito. Por isso, um sistema de valores centrado nos outros, evidenciando uma preocupação com o bem-estar colectivo, deverá favorecer uma gestão socialmente responsável, dado significar o mesmo esforço moral de integração de interesses alheios em decisões que afectam o interesse próprio.

HB 2: Os valores pessoais centrados na estabilidade e no conservadorismo influenciam positivamente uma atitude gerencial que favoreça o equilíbrio entre os compromissos sociais da empresa.

O cumprimento da lei, o respeito por valores socialmente transmitidos e a prevenção de danos sociais ou ambientais decorrentes da actividade empresarial constituem eixos essenciais dos compromissos legal e ético subjacentes à RSE. Um sistema pessoal de valores que defenda a conformidade com os desejos colectivos deve, portanto, constituir um estímulo significativo ao desenvolvimento de uma atitude gerencial que busca a estabilidade geral, capaz de subjugar o interesse próprio ao superior interesse de todos, favorecendo desta forma uma aproximação das práticas empresariais aos princípios vinculadores da RSE. 
HB 3: Os valores pessoais centrados no bem-estar individual influenciam negativamente uma atitude gerencial que favoreça o equilíbrio entre os compromissos sociais da empresa.

A natureza específica da actividade empresarial e a exigência de prestação de contas perante os investidores favorece que seja eleita como prioridade natural da acção gerencial a busca de crescimento económico e de sustentabilidade financeira do negócio. Assim, a atenção ao compromisso económico inerente à RSE parece naturalmente assegurada pelo quadro habitual de atribuições da função gerencial num sistema capitalista tradicional. A RSE representa uma pressão adicional principalmente nos casos do compromisso legal e, sobretudo, do compromisso ético, os quais implicam uma escolha menos natural e integradora de interesses alheios frequentemente conflituantes com a finalidade económica. Um sistema de valores centrado no êxito pessoal e na progressão social do próprio agente deverá, por isso, contribuir para perpetuar uma atitude gerencial que desvaloriza as responsabilidades sociais que comprometam os interesses dos accionistas e o crescimento da empresa, desfavorecendo o cumprimento equilibrado dos múltiplos compromissos subjacentes à RSE.

HB 4: Os valores pessoais centrados na independência de pensamento e de acção influenciam negativamente uma atitude gerencial que favoreça o equilibrio entre os compromissos sociais da empresa.

Num ambiente de negócios competitivo à escala global, as pressões para a inovação e para a adaptabilidade organizacional impõem-se como factores decisivos de sobrevivência, reforçando a centralidade do compromisso económico das empresas. O exigente equilíbrio de responsabilidades sugerido pela RSE requer uma atenção continuada aos impactos da acção empresarial, impondo, simultaneamente, uma ponderação e uma amplitude de finalidades que contrariam o desejo acelerado de mudança e a pressa do lucro sustentado. Por isso, um sistema de valores centrado na busca de novas experiências e na independência de acção, remetendo para um critério de decisão puramente individual, embora sintonizado com as tradicionais competências de um gestor, pode constituir um bloqueio à consolidação de uma atitude mais disponível à integração de preocupações sociais e ambientais nas práticas empresariais. 


\section{Estratégia metodológica: o recurso ao questionário e o Índice de Com- promisso Social dos Gestores (ICS)}

Para realizar o estudo empírico foi utilizado um questionário estruturado de resposta fechada. A avaliação do sistema de valores assentou numa versão adaptada do Portrait Values Questionnaire (PVQ) desenvolvido por Schwartz em 2001, destinado a medir o grau de importância atribuída pelo respondente a cada um dos dez tipos motivacionais de valores humanos. $\mathrm{Na}$ sua versão actual, mais reduzida, o PVQ é um questionário projectivo, composto por 21 itens que descrevem as preferências de 21 pessoas, sendo pedido ao respondente que indique o quanto cada uma dessas pessoas descritas se parece consigo. A versão usada nesta pesquisa foi adaptada para aplicação no contexto brasileiro (Almeida e Sobral, 2009), tendo o questionário sido traduzido para português e inquirindo os gestores directamente, abandonando assim o questionamento projectivo. Foram também simplificadas as duas frases originais de cada item em uma única frase, dado o próprio autor ter confirmado empiricamente que ambas medem o mesmo conceito e podem por isso ser fundidas numa só (Schwartz, 2003).

Para avaliar a atitude dos gestores perante a RSE, utilizou-se uma escala inspirada no instrumento desenvolvido por Aupperle, Carroll e Hatfield (1985) para medir a orientação da empresa em relação à RSE, baseado na concepção de Carroll (1979) sobre as responsabilidades sociais das empresas. $^{3} \mathrm{Na}$ versão agora usada, trata-se de uma escala de escolha forçada constituída por doze conjuntos de três itens, onde é requerido ao respondente que distribua 10 pontos por cada um desses conjuntos de acordo com o grau de importância relativa que atribui a cada item. Os três itens de cada conjunto descrevem acções ou objectivos empresariais concretos e correspondem aos três compromissos sociais da empresa (por exemplo: decidir em função das expectativas dos accionistas, decidir em função das exigências da lei, decidir em função das expectativas da sociedade).

Tendo em vista operacionalizar a escala de atitude perante a RSE e ler os resultados de acordo com o modelo proposto de RSE, construiu-se o Índice de Compromisso Social dos gestores empresariais (ICS). Este índice é um indicador quantitativo do comprometimento social de cada gestor, ou seja, uma medida da sua predisposição para exercer a administração de empresas de forma socialmente responsável, buscando na acção gerencial cumprir equilibradamente os três compromissos sociais das empresas:

\footnotetext{
${ }^{3}$ Numa extensa análise da literatura sobre RSE publicada ao longo de trinta anos (1972-2002), Carroll surge como o autor mais produtivo (com 10 trabalhos publicados), sendo o artigo de Aupperle, Carroll e Hatfield (1985) o mais citado de todos (Bakker et al., 2005) e o seu instrumento de pesquisa um dos mais utilizados para estudar a orientação social das empresas (Acar et al., 2001).
} 
económico, legal e ético. O ICS é calculado para cada gestor a partir das suas respostas, variando entre 0 a 10 pontos. Quanto mais próximo de 10 se situar o ICS do gestor, menor é a distinção que ele faz na importância que atribui a cada um dos compromissos sociais das empresas, aproximando-se da atitude gerencial socialmente responsável que busca cumprir todas as responsabilidades simultaneamente. As três responsabilidades sociais são desta forma tratadas com igual peso, assumindo que a desvalorização de qualquer uma delas reduz inevitavelmente - e na mesma intensidade - a predisposição do gestor para o equilíbrio de compromissos que caracteriza uma gestão socialmente responsável.

O estudo empírico foi realizado em dezasseis turmas de MBA e Mestrado Executivo de escolas e universidades do Rio de Janeiro e de São Paulo, seleccionadas segundo o critério de acessibilidade e repartidas igualmente pelas duas cidades. A recolha de dados foi efectuada por meio do questionário, aplicado presencialmente em papel. Para assegurar que a amostra final incluía apenas gestores brasileiros com relevante experiência empresarial, foram apenas considerados elegíveis os questionários integralmente preenchidos por gestores de empresas privadas com fins lucrativos e que tenham pelo menos três anos de experiência profissional (para garantir um conhecimento mínimo do mercado e das implicações económicas e sociais das decisões empresariais). A amostra final é constituída por 252 gestores que cumpriam as estas condições.

\section{Resultados da pesquisa}

\subsection{A influência dos valores na atitude perante a RSE}

As hipóteses desta pesquisa (HB1, HB2, HB3 e HB4) referem-se às associações previstas entre o sistema de valores dos gestores (constituído pelos quatro VOS) e a sua atitude perante a RSE (definida pelo ICS). Para avaliar o sentido da influência da cada VOS sobre o ICS, procedeu-se à análise de correlações, obtendo os seguintes coeficientes de correlação de Pearson (após normalização das distribuições por exclusão de outliers):

TABELA 1 - Correlações entre VOS e ICS (coeficientes de correlação de Pearson)

\begin{tabular}{|c|c|c|c|c|}
\hline & $\begin{array}{c}\text { voS Bem-estar } \\
\text { Colectivo }\end{array}$ & $\begin{array}{c}\text { vos Bem-estar } \\
\text { Individual }\end{array}$ & $\begin{array}{c}\text { voS Estabilidade } \\
\text { e Conservadorismo }\end{array}$ & $\begin{array}{c}\text { VOS Independência } \\
\text { e Empreendedorismo }\end{array}$ \\
\hline Índice ICS & 0,106 & $-0,212^{* *}$ & $0,212^{* *}$ & $-0,108$ \\
\hline$N$ & 244 & 236 & 241 & 246 \\
\hline
\end{tabular}

** sig. $<0,01$ 
Como se constata, confirmam-se os sentidos previstos da relação entre variáveis nas $\mathrm{HB}$, com os VOS Bem-estar colectivo e Estabilidade e Conservadorismo a exercerem uma influência positiva no ICS, contrariamente aos VOS Bem-estar Individual e Independência e Empreendedorismo que exercem uma influência negativa. Estas correlações antagónicas confirmam também, mais uma vez, a oposição teórica entre os VOS de cada eixo de ordem superior, revelando a contradição de objectivos motivacionais que cada um encerra. No entanto, apesar da concordância de sentidos, apenas os VOS Bem-estar Individual e Estabilidade e Conservadorismo apresentam associações estatisticamente significativas com o ICS, curiosamente simétricas, parecendo confirmar as hipóteses HB2 e HB3.

Para comparar a influência dos VOS no ICS, procedeu-se à regressão linear múltipla, segundo o método stepwise, segundo o qual se obtém uma equação de regressão onde se incluem apenas variáveis independentes com um efeito estatisticamente significativo na variável dependente. Eis os principais resultados obtidos no teste deste modelo de regressão:

TABELA 2 - Resultados da Regressão Múltipla

\begin{tabular}{|lcc|}
\hline \multicolumn{1}{|c|}{ Variáveis independentes incluídas } & vos Bem-estar Individual & $\begin{array}{c}\text { VOS Estabilidade } \\
\text { e Conservadorismo }\end{array}$ \\
\hline Sig. F change & 0,001 & 0,013 \\
Teste de tolerância (multicolinearidade) & 0,938 & 0,938 \\
Coeficiente $\beta$ estandardizado & $-0,167$ & 0,164 \\
Coeficiente de determinação múltipla $\mathrm{R}^{2}$ & $4,3 \%$ & $2,5 \%$ \\
\hline Rácio F (modelo 2) & \multicolumn{2}{c|}{8,450 (sig. 0,000) } \\
Durbin-Watson & \multicolumn{2}{c}{2,076} \\
\hline
\end{tabular}

Os resultados mostram que apenas os VOS Bem-estar Individual e Estabilidade e Conservadorismo são retidos no modelo como variáveis determinantes do ICS, confirmando o resultado das correlações ${ }^{4}$ e a validade das hipóteses HB2 e HB3, rejeitando as restantes. ${ }^{5}$ Os coeficientes $\beta$ estandardizados confirmam que o VOS Bem-estar Individual se correlaciona

\footnotetext{
${ }^{4}$ Foram verificados os pressupostos de homocedasticidade, de covariância nula entre as variáveis aleatórias residuais (confirmado pelo teste Durbin-Watson próximo de 2) e de não multicolinearidade (testes de Tolerância próximos de 1, confirmando a independência das variáveis explicativas). ${ }^{5} \mathrm{O}$ teste $\mathrm{F}$ do modelo 2 (incluindo os dois VOS) tem associado um nível de significância inferior a 0,05, permitindo rejeitar a hipótese nula de que os coeficientes de correlação múltipla sejam zero na população de onde a amostra foi retirada, ou seja, confirma a significância estatística do modelo com as duas variáveis retidas. Os indicadores de Sig. F change revelam igualmente o impacto estatisticamente significativo da introdução de ambas as variáveis no modelo (sig. $<0,05$ ), confirmando o resultado do teste $\mathrm{F}$.
} 
negativamente e o VOS Estabilidade e Conservadorismo se correlaciona positivamente com o ICS. Apesar da significância, o coeficiente de determinação múltipla $\mathrm{R}^{2}$ - que mede o quanto as variáveis independentes explicam a variável dependente - apresenta valores muito baixos, com ambos os VOS a explicarem apenas $6,8 \%$ da variância total do modelo. Isto significa que, embora se confirme empiricamente a relação entre as variáveis, o sistema de valores dos gestores não parece constituir um factor amplamente determinante da sua atitude perante a RSE.

\subsection{O efeito diferenciador da idade}

Análises adicionais aos dados revelaram que, embora não produza um impacto directo significativo no ICS, a idade dos gestores constitui um factor diferenciador da forma como o seu sistema de valores influencia a atitude perante a RSE. Para avaliar o impacto da idade nas HB, procedeu-se à análise separada de dois grupos etários de gestores: gestores com menos de 30 anos (120) e gestores com mais de 30 anos (132). Na Tabela 3 é apresentada uma síntese dos resultados destes testes. Por simplificação, apresentam-se os resultados em termos de equações nas quais se incluem apenas as variáveis independentes com capacidade explicativa estatisticamente significativa.

TABELA 3 - Resultados da Regressão Múltipla com o moderador Idade

\begin{tabular}{|c|c|c|}
\hline Amostra Global & $\begin{array}{c}\text { Menos de } 30 \text { anos } \\
(n=120)\end{array}$ & $\begin{array}{c}\text { Mais de } 30 \text { anos } \\
(n=132)\end{array}$ \\
\hline $\mathrm{ICS}=-\mathrm{BI}+\mathrm{EC}(6,8 \%)$ & $\mathrm{ICS}=+\mathrm{EC}-\mathrm{BI}(20,8 \%)$ & $\mathrm{ICS}=\varnothing$ \\
\hline
\end{tabular}

Legenda: ICS - Índice de Compromisso Social; EC-VOS Estabilidade e Conservadorismo; BI-VOS Bem-Estar Individual. Nota: As percentagens apresentadas entre parêntesis referem-se à parcela da variância total explicada pelo modelo

Ao analisar os resultados, verifica-se que a introdução do factor moderador idade reforça significativamente a capacidade explicativa do modelo (passando de 6,8\% para 20,8\%), retendo as mesmas variáveis independentes. Parece assim existir uma distinção clara na forma como os gestores com menos e com mais de 30 anos fundamentam o seu posicionamento perante a RSE. A atitude perante a RSE dos gestores mais velhos parece ser indiferente ao seu sistema de valores, sendo o modelo teórico aparentemente aplicável apenas ao grupo de gestores mais jovens.

\subsection{Síntese analítica: valores pessoais, atitudes e responsabilidade social}

De acordo com os resultados obtidos, o modelo proposto foi parcialmente validado, confirmando a relevância de analisar a atitude dos gestores perante a RSE a partir do seu sistema de valores pessoais. Os resultados mostram 
uma influência estatisticamente significativa dos VOS Bem-estar Individual e Estabilidade e Conservadorismo no Índice de Compromisso Social dos gestores. Assim, por um lado, o comprometimento social dos gestores parece favorecido por um sistema de valores conservadores, respeitadores da tradição, que prefere a obediência a normas e a convenções à exposição a novas experiências e desafios. Por outro lado, esse comprometimento parece ser desfavorecido por um sistema de valores centrados no bem-estar individual, orientados para a conquista de poder sobre pessoas e sobre recursos e para a realização profissional. Os dados corroboram o efeito contrário sobre a RSE provocado pelo antagonismo entre as concepções auto-centradas e hetero-centradas das relações humanas. Os princípios gerais que fundamentam e justificam o amplo conceito da RSE parecem desta forma basear-se num sistema axiológico centrado na vontade colectiva, baseado numa concepção universalista do mundo, que integra os interesses alheios nas decisões individuais, sobrepondo a harmonia colectiva ao benefício privado enquanto critério de acção e de decisão.

O VOS Estabilidade e Conservadorismo representa uma preferência axiológica contrária ao desejo de independência e de mudança, ou seja, caracteriza uma preferência pela estabilidade, alcançada por meio da acomodação das condutas individuais a normas sociais, do respeito pela tradição e da preservação da segurança colectiva em face de perturbações que a comprometam. Trata-se de valores centrados na vontade colectiva, por oposição à autonomia individual. A RSE, por definição, vincula as empresas à obrigação de atenderem múltiplos interesses, compatibilizando benefícios privados com o bem comum. É portanto compreensível que a valorização da estabilidade social e do cumprimento de normas colectivas favoreça uma atitude gerencial que atenda não apenas os interesses imediatos dos accionistas ou dos membros da organização, mas inclua igualmente nas decisões de gestão os interesses mais vastos da sociedade. No caso desta amostra de gestores brasileiros, a explicação deste resultado pode ter raízes ainda mais profundas, culturalmente determinadas. O personalismo e a cordialidade atribuídos ao povo brasileiro como traço distintivo da sua cultura (Holanda, 2003) conferem uma propensão especial para a adesão a valores opostos ao VOS Estabilidade e Conservadorismo, preferindo a independência de pensamento, a autonomia emocional e a liberdade de escolha dos vínculos pessoais. Este quadro de preferências axiológicas favorece um tipo de individualismo que responsabiliza cada pessoa pelo seu próprio destino e que, no plano organizacional, concebe a empresa como entidade que responde exclusivamente a interesses privados, afastando-se da concepção integradora de responsabilidades que a RSE inspira. 
Por isso, no Brasil, a sensibilidade a valores conservadores poderá constituir um factor crítico para explicar a adesão pessoal aos fins altruístas da RSE, que forçam a um universalismo que é estranho à pretensa vocação relacional do seu povo. Ou seja, tal como sugerem os resultados, é o reforço excepcional dos valores conservadores, contrários à presumida natureza informal do brasileiro, que maior impacto deve ter na adesão ao exigente compromisso, também ele excepcional, subjacente à RSE.

Mas esta influência do sistema de valores parece verificar-se, no entanto, apenas entre os gestores mais jovens. Uma explicação para este resultado pode decorrer do papel crescentemente estratégico que a RSE vem assumindo como instrumento de gestão e de política activa de sustentabilidade empresarial. A RSE tornou-se um poderoso e indispensável elemento de legitimação da acção das empresas, podendo as práticas socialmente responsáveis constituir um meio decisivo de auto-promoção e de diferenciação no mercado global. Neste cenário, é previsível que os gestores mais jovens, ainda menos conscientes das implicações estratégicas da RSE e menos expostos ao pensamento dominante no ambiente empresarial, recorram mais ao seu sistema de crenças pessoal para definir um posicionamento em relação às responsabilidades que vinculam as empresas perante a sociedade. Os gestores mais velhos, por seu lado, com mais experiência e com responsabilidades hierarquicamente superiores, tenderão a encarar a RSE como um instrumento de gestão e de resposta social sem implicações morais, substituindo os seus valores e a sua ética pessoal por um pensamento estratégico esclarecido.

Esta interpretação parece ser confirmada pelo amplo estudo realizado por Thiry-Cherques (2004), envolvendo mais de dois mil gestores, no qual o autor oferece uma reflexão detalhada sobre o quadro de referência ética dos jovens executivos brasileiros com menos de 30 anos. O autor confirma que este grupo etário parece ser caracterizado por normas e princípios diversos dos que animam a classe dirigente mais velha, explicado em parte porque a geração mais nova, dada a sua inexperiência e juventude, ainda se encontra em processo de consolidação de valores e em busca de uma referência moral que oriente as suas decisões gerenciais no complexo mundo da economia e das empresas. Segundo o autor, ao longo do processo de ascensão funcional, o jovem executivo cumpre um rito de passagem no qual interioriza os valores, os códigos morais e os modelos de conduta inerentes ao exercício do poder organizacional. Actualmente, no caso dos executivos brasileiros, este rito iniciático parece já não corresponder à transmissão de valores éticos, deixando os jovens executivos numa espécie de deriva moral (Thiry-Cherques, 2004). Os executivos mais jovens tendem por isso a aderir 
às correntes mais conservadoras do relativismo tradicionalista e da moral religiosa. A constatação da volatilidade dos juízos morais absolutos ao longo da história e a incerteza dos tempos modernos sobre o que antes se acreditava objectivo e demonstrável parece forçar os jovens a se "socorrerem na moral familiar da tradição e da religião para se orientar eticamente" (Thiry-Cherques, 2004: 627). Mas este apego à tradição e à religião exclui, e até se opõe, à moral tutelar da religião institucionalizada, normativa. Nos jovens executivos, cumprindo um desejo fundamental de eliminar a incerteza, a tradição refere-se ao carácter de permanência que atribuem aos valores essenciais que defendem e a religião refere-se à religiosidade, à sacralização de determinados valores, em busca da superação das transgressões que reconhecem na ética da vida social e organizacional.

\section{Conclusão}

Centrada no sistema de crenças e circunscrita ao pensamento dos gestores em contexto empresarial, esta pesquisa visou conhecer como o sistema de valores pessoais dos gestores influencia a sua atitude perante os compromissos subjacentes à RSE. Efectivamente, a RSE pode ser analisada não só a partir das acções e das políticas empresariais, mas também a partir das percepções éticas individuais de quem gere estas organizações. Elas revelam a intenção original e são um indicador importante dos princípios que orientam a decisão, desvendando, por isso, a acção provável.

O teste empírico das hipóteses sobre a influência do sistema de valores dos gestores na sua atitude perante a RSE revelou que um sistema de valores conservador influencia positivamente o comprometimento gerencial, o qual é inibido por valores que visem a auto-promoção e o bem-estar individual. Estes resultados reforçam a concepção da RSE como prolongamento organizacional de uma ética pessoal universalista. No caso específico dos gestores brasileiros estudados nesta pesquisa, integrados numa cultura supostamente avessa à formalidade das relações sociais e à submissão do desejo individual perante a vontade colectiva (Holanda, 2003), o conservadorismo representará uma excepção que contraria o tradicional personalismo da sociedade a que pertencem. Por isso os valores conservadores, ao implicarem um deslocamento da centralidade atribuída ao indivíduo para uma valorização do interesse comum, promovem também, no plano organizacional, uma integração de interesses mais amplos nas decisões gerenciais, alargando o grupo de stakeholders perante os quais a empresa se impõe responder.

A relação entre o sistema de valores e a atitude perante a RSE apenas se verificou, no entanto, no grupo de gestores com menos de 30 anos, sendo aparentemente inexistente no grupo de gestores mais velhos. Este resultado 
sugere que os gestores mais jovens, por inexperiência gerencial ou por adesão ainda precária ao pensamento dominante da classe, tendem a valorizar mais do que os gestores mais velhos a sua concepção moral do mundo como critério de decisão perante os dilemas que afectam a RSE. O envelhecimento e o amadurecimento profissional parecem eliminar, aos poucos, os fundamentos éticos e axiológicos da responsabilidade social. Com o aumento da experiência no mundo organizacional, os gestores abandonam a ética pessoal como critério de decisão e as práticas socialmente responsáveis tornam-se um instrumento de gestão que depende essencialmente de factores e de condicionantes contextuais. A RSE deixa de ser uma escolha moral para passar a ser uma opção estratégica, prevalecendo as razões de mercado sobre as razões éticas. Embora inesperado, este é um resultado interessante, cuja explicação pode contribuir para uma compreensão mais abrangente do fenómeno da RSE, merecendo por isso uma reflexão mais profunda e estudos adicionais.

\section{Referências bibliográficas}

Acar, William et al. (2001), "An Empirical Exploration of Measures of Social Responsibility Across the Spectrum of Organizational Types”, The International Journal of Organizational Analysis, 9(1), 26-57.

Allport, Gordon et al. (1960), A Study of Values. Boston: Houghton Mifflin.

Almeida, Filipe; Sobral, Filipe (2009), "O sistema de valores pessoais dos administradores brasileiros: uma adaptação da escala PVQ para o contexto brasileiro”, Revista de Administração Mackenzie. São Paulo: Editora Mackenzie, 10(3), 101-126.

Aupperle, Kenneth et al. (1985), "An Empirical Investigation of the Relationship Between Corporate Social Responsibility and Profitability”, Academy of Management Journal, 28(2), 446-463.

Bakker, Frank et al. (2005), "A Bibliometric Analysis of 30 Years of Research and Theory on Corporate Social Responsibility and Corporate Social Performance”, Business ESociety, 44(3), 283-317.

Banerjee, R. P. (2004), "Beyond Human Values: Divine values for new era corporations", in Ananda Das Gupta (org.), Human Values in Management. Aldershot: Ashgate, 112-126.

Bhatta, C. Panduranga (2004), "Effective Leadership: Human Values Perspective", in Ananda Das Gupta (org.), Human Values in Management. Aldershot: Ashgate, 223-240.

Bigoness, William; Blakely, Gerald (1996), "A Cross-National Study of Managerial Values", Journal of International Business Studies, 27(4), 739-752.

Birou, Alain (1976), Dicionário das Ciências Sociais, $2^{\mathrm{a}}$ ed., trad. de Alexandre Gaspar et al. Lisboa: Publicações Dom Quixote. 
Carroll, Archie (1979), “Three-Dimensional Conceptual Model of Corporate Social Performance", Academy of Management Review, 4, 497-505.

Carroll, Archie (1991), "The Pyramid of Corporate Social Responsibility: Toward the Moral Management of Organizational Stakeholders”, Business Horizons, 34(4), $39-48$.

Carroll, Archie (1999), "Corporate Social Responsibility: Evolution of a Definitional Construct”, Business \& Society, 38(3), 268-295.

Eisenhardt, Kathleen (1989), “Agency Theory: An Assessment and Review”, Academy of Management Review, 14(1), 57-74.

Esparza, Luis; Fernández, Luis (2002), "Valores individuales y valores corporativos percibidos: una aproximación empírica”, Revista de Psicología Social Aplicada, 12(1), 41-59.

Ferrell, O. C. et al. (2002), Business Ethics: Ethical Decision Making and Cases, $5^{\mathrm{a}} \mathrm{ed}$. Boston: Houghton Mifflin Company.

Fishbein, Martin; Ajzen, Icek (1975), Belief, Attitude, Intention and Behavior: An Introduction to Theory and Research. Reading, Massachusetts: Addison-Wesley.

Hemingway, Christine; Maclagan, Patrick (2004), “Managers' Personal Values as Drivers of Corporate Social Responsibility”, Journal of Business Ethics, 50(1), 33-44.

Holanda, Sérgio Buarque de (2003), Raízes do Brasil, 26ª ed., 17 reimp. São Paulo: Companhia das Letras.

Houaiss, Antônio (2002), Dicionário Houaiss da Língua Portuguesa. Rio de Janeiro: Instituto Antônio Houaiss de Lexicografia.

Kisil, Marcos (2005), Comunidade: foco de filantropia e investimento social privado. São Paulo: Global Editora; Porto Alegre: IDIS - Instituto para o Desenvolvimento do Investimento Social.

Kluckhohn, Clyde (1951), "Values and Value-Orientation in the Theory of Action: An Exploration in Definition and Classification”, in Talcott Parsons; Edward A. Shils (org.), Toward a General Theory of Action. Cambridge, MA: Harvard Business Press, 388-433.

Knafo, Ariel; Schwartz, Shalom (2001), "Value Socialization in Families of Israeli-born and Soviet-born Adolescents in Israel”, Journal of Cross-Cultural Psychology, 32(2), 213-228.

Kozan, M. Kamil; Ergin, Canan (1999), “The Influence of Intra-Cultural Value Differences on Conflict Management Practices”, International Journal of Conflict Management, 10(3), 249-267.

Maclagan, Patrick (1998), Management and Morality. London: Sage.

Munene, John et al. (2000), "Development in Sub-Saharan Africa: Cultural Influences and Managers' Decision Behaviour", Public Administration E Development, 20(4), 339-351.

Rohan, Meg (2000), “A Rose by Any Name? The Values Construct”, Personality and Social Psychology Review, 4(3), 255-277. 
Schwartz, Shalom (1992), "Universals in the Structure and Content of Values: Theoretical advances and empirical tests in 20 countries", in Mark Zanna (org.), Advances in Experimental Social Psychology, 25. Orlando: Academic Press, 1-65.

Schwartz, Shalom (1994), "Beyond Individualism/Collectivism: New Cultural Dimensions of Values”, in Uichol Kim et al. (org.), Individualism and Collectivism: Theory, Method and Applications. Newbury Park: Sage Publications, 85-119.

Schwartz, Shalom et al. (2001), "Extending the Cross-Cultural Validity of the Theory of Basic Human Values with a Different Method of Measurement", Journal of Cross-Cultural Psychology, 32(5), 519-542.

Schwartz, Shalom (2003) “A Proposal for Measuring Value Orientations Across Nations”, in The Questionnaire Development Package of the European Social Survey, 2003. Disponível em: http://www.europeansocialsurvey.org (acedido a 29/07/2009).

Schwartz, Shalom (2005), "Valores Humanos Básicos: Seu contexto e estrutura intercultural”, trad. Viviane Rios, in Álvaro Tamayo; Juliana Porto (org.), Valores e comportamento nas organizações. Petrópolis, RJ: Vozes, 21-55.

Smith, Peter et al. (2002), "Cultural Values, Sources of Guidance, and Their Relevance to Managerial Behavior: A 47-nation study”, Journal of Cross-Cultural Psychology, 33(2), 188-208.

Sousa, Carlos; Bradley, Frank (2002), “An Assessment of Value Structure and Content in Ireland”, Irish Journal of Management, 23(1), 109-123.

Spini, Dario (2003), "Measurement Equivalence of 10 Value Types from the Schwartz Value Survey Across 21 Countries”, Journal of Cross-Cultural Psychology, 34(1), 3-23.

Tamayo, Álvaro et al. (2001), "Prioridades axiológicas e comprometimento organizacional”, Psicologia: Teoria e Pesquisa, 17(1), 27-35.

Thiry-Cherques, Hermano (2003), "Responsabilidade Moral e Identidade Empresarial”, Revista de Administração Contemporânea, Edição Especial, 31-50.

Thiry-Cherques, Hermano (2004), "O conformismo impaciente: Uma interpretação do quadro de referência ética dos jovens executivos nas organizações brasileiras”, Revista de Administração Pública, 38(4), 613-642.

Trevino, Linda (1986), "Ethical Decision Making in Organizations: A person-situation interactionist model”, Academy of Management Review, 11(3), 601-617.

Vergara, Sílvia (2004), "Olga: A semeadora de grãos e de responsabilidade social na história do Grupo Nova América”, Organização \& Sociedade, 11(31), 153-170.

Wartick, Steven; Cochran, Philip (1985), "The Evolution of the Corporate Social Performance Model”, Academy of Management Review, 10, 758-769.

Watson, Tony (2003), "Ethical Choice in Managerial Work: The Scope for Moral Choices in an Ethically Irrational World”, Human Relations, 56(2), 167-185.

Wood, Donna (1991), "Corporate Social Performance Revisited”, Academy of Management Review, 16(4), 691-718. 